\title{
Getting the Most Out of Giving: Concretely Framing a Prosocial Goal Maximizes Happiness
}

\section{Citation}

Rudd, Melanie, Jennifer Aaker, and Michael I. Norton. "Getting the Most Out of Giving: Concretely Framing a Prosocial Goal Maximizes Happiness." Journal of Experimental Social Psychology (forthcoming).

\section{Permanent link}

http://nrs.harvard.edu/urn-3:HUL.InstRepos:12534961

\section{Terms of Use}

This article was downloaded from Harvard University's DASH repository, and is made available under the terms and conditions applicable to Open Access Policy Articles, as set forth at http:// nrs.harvard.edu/urn-3:HUL.InstRepos:dash.current.terms-of-use\#OAP

\section{Share Your Story}

The Harvard community has made this article openly available.

Please share how this access benefits you. Submit a story. 
Getting the Most out of Giving:

Concretely Framing a Prosocial Goal Maximizes Happiness

\author{
Melanie Rudd ${ }^{\mathrm{a}}$ \\ University of Houston \\ Jennifer Aaker ${ }^{\mathrm{b}}$ \\ Stanford University \\ Michael I. Norton ${ }^{\mathrm{c}}$ \\ Harvard Business School
}

${ }^{\mathrm{a}}$ C. T. Bauer College of Business, University of Houston, 334 Melcher Hall, Houston, TX 77204; Email: mrrudd@bauer.uh.edu

${ }^{\mathrm{b}}$ Graduate School of Business, Knight Management Center, Stanford University, 655 Knight Way, Stanford, CA 94305; Email: jaaker@stanford.edu

${ }^{\text {c } H a r v a r d ~ B u s i n e s s ~ S c h o o l, ~ S o l d i e r s ~ F i e l d, ~ B o s t o n, ~ M A ~ 02163 ; ~ E m a i l: ~ m n o r t o n @ h b s . e d u ~}$

Author Note

Correspondence concerning this article should be addressed to Melanie Rudd, C. T. Bauer College of Business, 334 Melcher Hall, Houston, TX 77204-6021; Email: mrrudd@bauer.uh.edu; Phone: 713.743.4572. 


\begin{abstract}
Across six field and laboratory experiments, participants assigned a more concretely-framed prosocial goal (e.g., making someone smile or increasing recycling) felt happier and reported creating greater personal happiness after performing a goal-directed act of kindness than did those who were assigned a functionally similar, but more abstractly-framed, prosocial goal (e.g., making someone happy or saving the environment). Moreover, mediation analyses revealed that this effect was driven by differences in the size of the gap between participants' expectations and reality. Compared to those who pursued an abstractly-framed prosocial goal, those who pursued a concretely-framed goal perceived that the actual outcome of their goal-directed efforts more accurately matched their expectations, causing them to experience a greater boost in happiness. Evidence that participants are unable to predict this effect, believing that pursuing abstractlyframed prosocial goals would have either an equal or greater positive impact on their own happiness, is also presented.
\end{abstract}

Keywords: happiness, prosocial behavior, goal framing, affective forecasting 
Getting the Most out of Giving: Concretely Framing a Prosocial Goal Maximizes Happiness

For many people, the pursuit and attainment of happiness is one of the most essential quests in life. Indeed, the majority of surveyed Americans rate their personal happiness as being very important (Diener, Suh, Smith, \& Shao, 1995; Triandis, Bontempo, Leung, \& Hui, 1990) and report thinking about their happiness at least once each day (Freedman, 1978). But although the desire for personal happiness may be clear, the path to achieving it is indefinite.

One reason for this hazy route to happiness is that although people often think they know what leads to happiness, their predictions about what will make them happy are often inaccurate (Gilbert, 2006). Another obstacle is that many of the factors shown to drive happiness and wellbeing represent relatively stable aspects of an individual's life, such as the cultural environment in which one is raised or resides (Diener, 2000; Diener, Suh, Lucas, \& Smith, 1999) and demographics such as age, education, social class, marital status, and religion (Argyle, 1999; Diener et al., 1999; Mastekaasa, 1994; Myers, 2000). Because changing these circumstantial factors can be monetarily and temporally costly (and sometimes impossible), the results of these studies provide limited assistance to individuals who wish to achieve greater happiness in their daily lives. Furthermore, because people are quick to hedonically adapt to stable life circumstances (Brickman \& Campbell, 1971; Kahneman, 1999; Tversky \& Griffin, 1991), these types of factors may have fairly limited effects on long-term happiness (Lyubomirsky, Sheldon, \& Schkade, 2005). Thus, researchers have increasingly focused on identifying hedonically rewarding intentional activities (i.e., effortful actions or practices in which people actively choose to engage) that increase happiness, as they are more resilient to the effects of hedonic adaptation (Sheldon \& Lyubomirsky, 2006). 
One type of intentional activity that has received attention from happiness-related research is behaving prosocially. Indeed, the body of research on prosociality has shed some light on the question of how people can attain greater happiness, demonstrating that engaging in prosocial behaviors increases one’s well-being and happiness (Andreoni, 1989, 1990; Anik, Aknin, Norton, \& Dunn, 2009; Lyubomirsky, Tkach, \& Sheldon, 2004; Post, 2005; Rucker, DuBois, \& Galinsky, 2011). But are some prosocial pursuits better able to increase personal happiness than are others? We address this underexplored question in six experiments, examining one critical moderating factor in the causal link between prosocial acts and happiness: the perceived level of abstraction of the goal of the act. In particular, we suggest that acts designed to improve the well-being of others will lead to greater happiness for givers when these acts are associated with prosocial goals that are framed more concretely (versus abstractly).

\section{Prosocial Behavior Makes People Happier}

By their nature, prosocial acts are designed to directly benefit the well-being of the recipient. However, research has shown that prosocial acts can be hedonically beneficial for givers as well (Andreoni, 1989, 1990; Dunn, Aknin, \& Norton, 2008; Grant \& Sonnentag, 2010;

Rucker, DuBois, \& Galinsky). In the prosocial domain of volunteering, for example, both membership in service-oriented organizations and volunteer work have been associated with higher levels of life satisfaction, greater happiness, and fewer symptoms of depression (Thoits \& Hewitt, 2001; Van Willigen, 1998), and those who invest more hours of volunteering report greater psychological well-being (Morrow-Howell, Hinterlong, Rozario, \& Tang, 2003). Furthermore, acts of kindness and generosity increase the well-being of the instigator of the act. For instance, individuals who performed five random acts of kindness a week for six weeks were happier than those in a no-act control group (Lyubomirsky et al., 2005), and individuals who 
more frequently engaged in altruistic acts rate themselves higher on measures of well-being (Krueger, Hicks, \& McGue, 2001). Research on prosocial spending has uncovered similar hedonic effects. For example, individuals who use more financial resources to help others report increased feelings of happiness (Dunn et al., 2008). In sum, it appears the tendency for prosocial acts to impact personal happiness is present across a wide range of contexts and behaviors.

Further, there is growing evidence that such acts may do so just as (if not more) effectively than similar acts directly targeted at the self. For instance, charitable donations are associated with neural activation in brain regions that are implicated in the experience of pleasure and reward, a pattern of activation is similar to that which arises after receiving money for oneself (Harbaugh, Mayr, \& Burghart, 2007). Furthermore, spending money on others leads to higher levels of happiness than spending money on oneself (Dunn et al., 2008). However, given that prosocial (versus personally-targeted) acts appear to provide a superior path to happiness, a natural question arises: What other-focused pursuits have the biggest impact on one’s own happiness?

\section{Shrinking the Perceived Goal of the Prosocial Act}

The primary purpose of a prosocial act is to do something positive for another person. But as the above research demonstrates, positively impacting another person with a prosocial act can also increase one’s own personal happiness, creating a "helper’s high” (Luks, 1988) or “warm glow” (Andreoni, 1989; 1990) for a giver. We suggest that the hedonic benefit givers receive from their prosocial acts depends, at least in part, on the degree to which givers perceive that their actions had the desired prosocial effect (i.e., the extent to which they feel the outcome of their acts actually met their expectations for achieving their prosocial goal). One possible means of enhancing one's ability to meet these expectations is to "shrink" the prosocial goal's 
perceived magnitude by making it more concrete. Rather than aiming to achieve an abstractlyframed prosocial goal (e.g., help the environment or make someone happy), we suggest reframing this goal in functionally similar, but more concrete terms (e.g., increase recycling or make someone smile), as this might increase the extent to which a giver's hopes are met.

Goals often differ in their level of abstraction (Emmons, 1996; Emmons \& Kaiser, 1996; Oettingen \& Gollwitzer, 2001), and are framed in broad, abstract ways or specific, concrete ways. However, the framing of a goal can have important implications. For instance, striving for a variety of abstract goals has been associated with greater psychological distress, such as anxiety and depression, whereas striving for various concrete goals has been linked to psychological well-being (Carver, La Voie, Kuhl, \& Ganellen, 1988; Carver \& Scheier, 1990; Emmons, 1992). Building upon these results, we hypothesized that the amount of personal happiness created by an act of kindness could be increased by shifting the level of abstraction of the prosocial goal from a more abstract to a more concrete, but functionally similar, framing. Why might the level of abstraction at which a prosocial goal is framed influence one’s personal happiness? One possibility is that acts with more concretely-framed (versus abstractlyframed) prosocial goals lead to outcomes that are perceived as better meeting one's expectations for achieving that goal. This perceived discrepancy between one's expectations that an act will achieve a prosocial goal and the actual outcome of that act is referred to as an "expectationreality gap” (Michalos, 1980, 1985; Vermunt \& Steensma, 2001). Smaller expectation-reality gaps have been linked to greater satisfaction, happiness, and well-being (Christensen, Herskind, \& Vaupel, 2006; Davis, 1981; Gregg, 1972; Michalos, 1985; Schwartz, 2003; Thomas, 1981; Vermunt, Spaans, and Zorge, 1989). However, since people tend to possess inaccurate expectations about future outcomes (Buehler, Griffin, \& Ross, 2002; Weinstein, 1980; 
Zauberman \& Lynch, 2005), expectation-reality gaps are frequent. This raises the question of when expectation-reality gaps might be minimized.

According to prior research, two related factors appear to play a key role. One is expectation accuracy: There is a greater possibility that one's expectations will be met in reality if one is able to set more realistic expectations (Kopalle \& Lehmann, 2001; Schwartz, 2003). Two, the more that one's perception of the actual outcome can be shifted in the direction of one's expectations, the greater the likelihood that the outcome will be seen as meeting one's expectations (Ojasalo, 2001; Walker \& Baker, 2000).

Performing behaviors in pursuit of prosocial goals that are framed concretely (versus abstractly) may minimize the expectation-reality gaps for achieving prosocial goals due to both of these reasons. First, a more concretely-framed goal may lead to more accurately calibrated initial expectations for achieving the goal. When one is considering goal-related actions, an abstractly-framed goal encourages a focus on the why of the action (i.e., the broader meaning or larger purpose) whereas a concretely-framed goal focuses one more strongly on the how of the action (i.e., the details or logistics; Torelli \& Kaikati, 2009; Vallacher \& Wegner, 1987, 1989; Zhang, Fishbach, \& Dhar, 2007). Focusing on how one will attain an outcome, as opposed to why one is attempting to attain the outcome, can enable one to better anticipate potential obstacles as well as opportunities and means for executing the goal-directed behavior (Gollwitzer, 1993, 1996; Pham \& Taylor, 1999; Taylor, Pham, Rivkin, \& Armor, 1998)—all factors that enhance one's ability to accurately calibrate expectations.

Second, having a more concretely-framed (versus abstractly-framed) goal may shift the perceived quality of the actual outcome (i.e., the reality) of goal-related actions. Whether a particular outcome is an acceptable instance of goal attainment is often difficult to assess for 
abstract goals, due to vague standards of success (Emmons, 1992). More concretely-framed goals, on the other hand, permit less ambiguous feedback regarding how well the outcome of one's actions achieved the goal (Locke \& Latham, 1990). For instance, it is clear whether one has exercised at the gym or read the daily newspaper, but more difficult to assess whether one has lived a healthy lifestyle or increased one's knowledge of the world. When people feel more certain that an act of kindness had the desired effect, their perception of the outcome of the act should be more favorable and, thus, seen as better meeting their expectations.

Therefore, taking into account both strategies for minimizing expectation-reality gaps, we predicted that an act performed in pursuit of a more concretely-framed prosocial goal would enhance one's personal happiness more so than would an act performed in pursuit of a more abstractly-framed, but functionally similar, prosocial goal. Further, we predicted that the mechanism driving this greater personal happiness would be a reduced gap between givers’ expectations of accomplishing their prosocial goal and the actual outcome of their act.

\section{Predicting Personal Happiness from Prosocial Acts}

Despite the fact that prior research seems to support the notion that framing one's prosocial goals in more concrete terms is particularly beneficial for personal happiness, the pursuit of relatively broad and abstractly-framed prosocial goals-such as making others happy or saving the environment—is quite commonplace in modern society. This raises an important question: Do people recognize that framing prosocial goals more concretely is more hedonically advantageous than framing them more abstractly? Indeed, people often make inaccurate predictions about their happiness (Aknin, Norton, \& Dunn, 2009; Brickman, Coates, \& JanoffBulman, 1978; Dunn et al., 2008; Gilbert, 2006; Gilbert, Pinel, Wilson, Blumberg, \& Wheatley, 1998). Thus, we expected that, in line with the popular notions that "bigger is better" and one 
should “go big or go home,” people would not correctly predict that framing a prosocial goal more concretely (e.g., making someone else smile) would lead to greater personal happiness than would framing it in seemingly broader, more abstract terms (e.g., making someone else happy).

\section{Overview of Hypotheses}

Stated more formally, the hypotheses tested in the present research are:

H1: Performing an act designed to accomplish a prosocial goal will lead to greater personal happiness when that prosocial goal is framed in more concrete terms (e.g., make someone smile) than when the prosocial goal is framed in more abstract terms (e.g., make someone happy). H2: Framing a prosocial goal in more concrete terms (e.g., make someone smile) versus more abstract terms (e.g., make someone happy) will lead to greater personal happiness by reducing the gap between one's expectations of accomplishing the prosocial goal and the actual outcome of acts performed in service of that goal.

H3: People will inaccurately predict which prosocial goal framing will lead to the greatest personal happiness (e.g., incorrectly predicting that aiming to make someone happy would be either just as beneficial or better for personal happiness than aiming to make someone smile).

\section{Experiment 1}

The goal of Experiment 1 was to perform an initial test of whether performing an act in pursuit of a concretely-framed (versus a functionally similar, but more abstractly-framed) prosocial goal would lead to greater personal happiness (H1). To examine our first hypothesis, participants in Experiment 1 were randomly assigned to perform either an act designed to accomplish the prosocial goal of making someone happy (i.e., an abstractly-framed goal) or an act designed to accomplish the prosocial goal of making someone smile (i.e., a functionally similar, but more concretely-framed goal). 


\section{Method}

Participants and design. Fifty people from a national survey pool (62\% female, 38\% male; $M_{\text {Age }}=38.32, S D_{\text {Age }}=12.60$ ) participated in exchange for a $\$ 5$ Amazon.com gift card. The experiment used a 2 cell (Prosocial Goal: Smile vs. Happy) between-subjects design.

Procedure. Participants completed a two-part survey. In the first survey, they were informed that they would need to perform an act of kindness. To manipulate the prosocial goal of this act, participants randomly assigned to the happy [smile] goal condition were told, "In this study we ask you to accomplish a task: Do something to make someone else happy [smile].” All participants were instructed that they would have 24 hours to accomplish their task, at which point they would take part in a follow-up survey.

The follow-up survey, administered one day later, contained an item asking participants to briefly describe the act they performed, as well as filler items about the assigned task. Embedded in these filler items was the key measure of personal happiness. In regards to the act they performed, participants responded to the following item: “To what degree do you feel you created happiness in your own life?” (1 = not at all, 7 = very much). Last, as a manipulation check, participants reported the extent to which the act they performed was designed to elicit a smile $(1=$ not at all, $7=$ very much $)$ and happiness $(1=$ not at all, $7=$ very $m u c h)$.

\section{Results and Discussion}

Manipulation checks. An independent samples t-test on participants’ ratings of the goal of the act they performed confirmed that those in the smile $(M=6.42, S D=0.78)$ versus happy $(M=5.54, S D=1.61)$ goal condition performed acts of kindness that were designed, to a greater extent, to elicit a smile, $t(48)=-2.43, p=.02, d=.70$. Moreover, those in the happy $(M=6.38$, 
$S D=0.75)$ versus smile $(M=5.54, S D=1.50)$ goal condition performed acts of kindness that were designed, to a greater extent, to elicit happiness, $t(48)=2.54, p=.01, d=.71$.

Personal happiness. To test our hypothesis, an independent samples t-test was conducted on the personal happiness measure. The results revealed the predicted effect of prosocial goal abstraction, $t(48)=-2.87, p=.01, d=.83$. Participants in smile goal condition $(M$ $=6.50, S D=0.66$ ) felt they created more personal happiness with their act than did those in the happy goal condition $(M=5.50, S D=1.58)$.

Type of act performed. It could be argued that the two goal conditions differed not only in the level of abstraction at which the assigned prosocial goals were framed but also in the types of acts performed in each condition. If this were indeed the case, the observed effect of goal condition on personal happiness could be due to a difference in the types of acts performed by those in the two goal conditions. To address this alternative account, participants' descriptions of their acts were coded by two condition- and hypothesis-blind research assistants using a nonmutually exclusive system. The list of possible act types was developed by the researchers prior to running the experiment, and the act type categories $(0=n o, 1=y e s)$ that received at least one response were: gave someone a gift or trinket; told someone an amusing story or joke; gave someone food or drink; lent someone a helping hand; unexpectedly got in touch/reconnected with someone; gave someone a card; gave someone a compliment/said kind words to someone; shared an amusing video or picture with someone; lent someone an ear; engaged in physical contact with someone.

All descriptions were coded by at least one research assistant. Forty percent of descriptions were coded by both research assistants and the percent agreement between the two was 95\% (inter-rater reliability for all category ratings: ICCs $>.90, p s<.01$ ). Chi-square tests 
then examined the significance of differences in act type frequencies between the smile and happy goal conditions (see Table 1). The results revealed that the types of acts performed did not significantly differ across conditions, $\chi^{2} \mathrm{~s}<.32$, $p \mathrm{~s}>.57$, casting doubt on the possibility that the effects were driven by those in two conditions performing different types of acts.

Discussion. Experiment 1 demonstrated that performing an act of kindness is better for personal happiness when it is performed in pursuit of the prosocial goal of making someone else smile versus making someone else happy. These results therefore support the hypothesis that performing an act designed to accomplish a prosocial goal will lead to greater personal happiness when that goal is framed more concretely (versus abstractly). The question of why the pursuit of certain prosocial goals leads greater personal happiness for givers was explored in Experiment 2.

\section{Experiment 2}

Experiment 2 aimed to replicate the main result in Experiment 1 and investigate the mechanism underlying it. Specifically, Experiment 2 tested the hypothesis that the more concrete framing of the goal to make someone else smile (versus the more abstract framing of the goal to make someone else happy) would reduce the gap between one's expectations of accomplishing the prosocial goal and the perceived outcome of the act, and, in turn, generate greater personal happiness (H2). An additional objective was to more explicitly confirm that the two prosocial goals indeed differed in their perceived level of concreteness.

\section{Method}

Participants and design. One hundred and twenty-seven people from a national survey pool (71\% female, $29 \%$ male; $\left.M_{\text {Age }}=34.67, S D_{\text {Age }}=11.49\right)$ participated for a $\$ 5$ Amazon.com gift card. A 2 cell (Prosocial Goal: Smile vs. Happy) between-subjects design was used. 
Procedure. All participants completed a two-part survey. First, participants were asked to perform an act of kindness, keeping one of two possible goals in mind. Specifically, participants in the happy [smile] goal condition were told, "In this study we ask you to accomplish a task: Do something to make someone else happy [smile].” As in Experiment 1, all participants were then instructed that they would have 24 hours to accomplish their task, at which point they would take part in a follow-up survey.

One day later, participants received the follow-up survey, which asked them to describe the act they performed and respond to several filler items about the assigned task. Embedded in these filler questions were three key items. To measure feelings of personal happiness, the first item asked participants (in regards to the act of kindness they had performed) "To what degree do you feel you created happiness in your own life?” (1 = not at all, 7 = very much). The second item assessed the perceived size of the expectation-reality gap: "How well did the outcome of the act you performed meet your expectations of accomplishing your assigned goal?”; 1 = not at all, 7 = very well). Last, participants reported their perceptions of how specific the goal that they had in mind was when they performed their act $(1=$ not at all, $7=$ very $)$.

\section{Results and Discussion}

Manipulation check. Ratings concerning participants’ perceptions of the specificity of the goal they had in mind when performing their act confirmed that the level of goal abstraction manipulation was successful: Those in the smile goal condition $(M=5.41, S D=2.12)$ felt they had a more specific goal in mind when they performed their act than did those in the happy goal condition $(M=4.53, S D=1.97), t(125)=-2.43, p=.02, d=.43$.

Expectation-reality gap. An independent samples t-test was conducted on the measure of the perceived gap between expectations and reality. This analysis revealed the predicted effect 
of prosocial goal condition, $t(125)=-3.34, p<.01, d=.60$. The smile goal participants $(M=$ $6.51, S D=0.86$ ) perceived that the outcome of their act better met their expectations for accomplishing their prosocial goal than did the happy goal participants $(M=5.92, S D=1.10)$. A correlation analysis further supported this effect: Across conditions, having a more specific prosocial goal in mind when the act was performed was associated with act's outcome better meeting one's expectations, $r=.36, p<.01$.

Personal happiness. The results of an independent samples t-test revealed the predicted effect of prosocial goal condition, $t(125)=-2.21, p=.03, d=.39$. Participants in the smile goal condition $(M=5.95, S D=1.14)$ felt that their act created more personal happiness than did those in the happy goal condition ( $M=5.52, S D=1.08)$. Further, a correlation analysis supported our account of this effect: Across conditions, greater perceived prosocial goal specificity was associated with greater personal happiness $(r=.32, p<.01)$.

Next, a mediation analysis was conducted. We employed nonparametric bootstrapping procedures to calculate this indirect effect using PROCESS in SPSS, a computational tool for observed variable mediation (Hayes, 2013). Bootstrapping provided a confidence interval (CI) around the indirect effect of the independent variable (goal condition) on the dependent variable (personal happiness) via the mediator (expectation-reality gap size). The results showed that those in the smile (versus happy) goal condition did indeed feel their act created more personal happiness as a result of their smaller expectation-reality gaps (i.e., because the outcome of their acts better met their expectations of accomplishing their goal; $\beta=.16 ; 95 \% \mathrm{CI}$ of indirect effect: LLCI $=0.03$ and ULCI $=0.39$ ).

Type of act performed. As in Experiment 1, participants' act descriptions were coded by two condition- and hypothesis-blind research assistants using a non-mutually exclusive system. 
The list of possible act types was developed by the researchers prior to running the experiment, and the act type categories $(0=n o, 1=y e s)$ that received at least one response were: gave someone a gift or trinket; told someone an amusing story or joke; gave someone food or drink; lent someone a helping hand; unexpectedly got in touch/reconnected with someone; gave someone a compliment/said kind words to someone; shared an amusing video or picture with someone; engaged in physical contact with someone; performed an amusing skill or talent for someone; participated in an activity or hobby with someone.

All descriptions were coded by at least one research assistant. Forty percent of descriptions were coded by both research assistants and the percent agreement between the two was 94\% (inter-rater reliability for all category ratings: ICCs $>.90$, ps $<.01$ ). Chi-square tests then examined the significance of differences in act type frequencies between the smile and happy goal conditions (see Table 2). The results of these analyses revealed that the types of acts performed did not significantly differ across conditions, $\chi^{2} s<1.02$, $p s>.31$, indicating the effects were not driven by those in the two conditions performing different types of acts.

Discussion. Experiment 2 provided further evidence that that shifting away from a more abstract framing of a prosocial goal (e.g., making someone else happy), and instead framing the goal in more concrete terms (e.g., making someone else smile) can increase the happiness experienced by those performing prosocial acts. Moreover, a mediational analysis supported the proposed mechanism: The boost to personal happiness brought about by the more concretelyframed prosocial goal was driven by the actual outcome of the goal-directed act better meeting one’s expectations for accomplishing the prosocial goal.

\section{Experiment 3}


Experiment 3 used a dyad experimental design in a controlled laboratory setting so as to both replicate the basic effect and further examine several alternative accounts for it. For instance, it could be argued that, in the prior experiments, the greater personal happiness experienced by those in the smile (versus happy) prosocial goal condition was actually due to those in the smile (versus happy) goal condition a) targeting their act at different recipients (e.g., a stranger versus a friend), b) performing acts that they perceived as being of a different size or scale, and/or c) differing in the extent to which they made their recipients feel happy. Thus, Experiment 3 addressed these alternative explanations by a) controlling for the type of relationship givers had with recipients (i.e., all givers and recipients were friends) and measuring givers' perceptions of how close they felt to their recipient, b) measuring givers’ perceptions of the size of the act they performed, and c) measuring how happy recipients felt after the givers performed their acts of kindness. An additional goal was to obtain participants’ predictions about the prosocial goal to which they had been assigned and, for convergent validity (and due to the fact that the laboratory setting would allow for a shorter time-delay between when the act of kindness was performed and the completion of the follow-up survey), a different measure of personal happiness was used. Finally, we note that while we relied on self-reports of participants’ prosocial acts in Experiments 1 and 2, in Experiment 3 we were able to ensure that participants completed their assigned actions by moving the paradigm into a controlled laboratory setting.

\section{Method}

Participants and design. Sixty pairs of friends (120 individuals in total), all university students ( $49 \%$ female, $52 \%$ male; $\left.M_{\text {Age }}=21.28, S D_{\text {Age }}=3.06\right)$, participated in exchange for $\$ 15$ (per person). A 2 cell (Prosocial Goal: Smile vs. Happy) between-subjects design was used. 
Procedure. All participants completed two surveys. Shortly after arriving at the laboratory, the friends were placed in separate experimental rooms. Within each pair of friends, one participant was randomly assigned to the role of "giver," and the other to the role of "receiver" (participants were not informed of the role to which they had been assigned). All participants then completed the first survey, where they answered questions about their relationship to the person with whom they were participating, including a 2-item perceived closeness index ("How close do you feel to the friend you are participating in this study with?" and "How personally connected are you to the friend you are participating in this study with?”; 1 $=$ not at all, $7=$ extremely; $\left.\alpha_{\text {Giver }}=0.94, \alpha_{\text {Recipient }}=0.90\right)$ and reported the number of years they had known their friend.

Next, all participants were told there would be a three-minute break before they completed the second survey, and that during this break they would be placed in a room with their friend. The giver in each pair was then provided with additional instructions: They were asked to try to accomplish one of two prosocial goals by performing an act of kindness for their friend during the break. Participants randomly assigned to the happy [smile] goal condition were provided with the prosocial goal of "making their friend happy [smile].” The participants were then led from their separate experimental rooms and placed together in the same private room, where the "giver" attempted to achieve their assigned prosocial goal.

Three minutes later, both participants were escorted back to their separate experimental rooms to complete the second survey. For givers, the second survey contained an item asking them to briefly describe the act they performed as well as filler items about the assigned task, embedded in which were eight key items. To measure personal happiness, givers responded to the following item: “How happy are you right now?” (1 = not at all, 7 = extremely). A second 
item assessed the perceived size of the expectation-reality gap (this measure was the same as the one used in Experiment 2). Givers also reported their perceptions of the size of the act that they performed ("To what extent do you feel that what you did during the break in order to try to accomplish your assigned goal was something small or something big?”; 1 = very small, 7 = very big). To determine whether people would accurately predict which prosocial goal framing is the most personally advantageous, givers also responded to several items that asked them their initial predictions about their assigned prosocial goal (i.e., how they perceived their assigned prosocial goal prior to the three minute break). These items were: “To what extent did you think you would be able to accomplish the assigned goal?” (1 = not at all, 7 = very much), “To what extent did you expect to succeed at accomplishing the assigned goal” ( 1 = not at all, 7 = very much), and "How challenging did you think it would be to accomplish the assigned goal?" $(1$ = not at all, $7=$ very). Last, givers reported their perceptions of the specificity of goal they had in mind during the three minute break ( 1 = not at all, 7 = very) and how concrete or abstract they felt the goal they had in mind was $(1=$ very concrete, 7 = very abstract $)$.

For receivers, the second survey contained filler items, embedded in which were three key items. Specifically, receivers responded to items asking “How happy are you right now?” (1 = not at all; 7 = extremely), "How much did you smile while interacting with your friend during the break?” (1 = not at all; 7 = very), and “To what extent did you feel happy while interacting with your friend during the break?” (1 = not at all; 7 = very).

\section{Results and Discussion}

Manipulation check. An independent samples t-test conducted on givers’ ratings of their perceptions of the specificity and concreteness of their goal during the three minute break confirmed that the level of goal abstraction manipulation was successful. Those in the smile goal 
condition $(M=6.32, S D=0.87)$ felt they had a more specific goal in mind when performing their act than did those in the happy goal condition $(M=5.45, S D=1.38), t(58)=2.96, p<.01, d$ $=.75$. Those in smile goal condition $(M=2.32, S D=1.54)$ also perceived their goal as more concrete (versus abstract) than did those in the happy goal condition $(M=3.41, S D=1.78), t(58)$ $=-2.55, p=.01, d=.65$.

Pair relationship. All participant pairs were comprised of friends, and ratings concerning the relationships of the participant pairs revealed that givers in the smile (versus happy) goal condition were not targeting their acts at people with whom they were differentially familiar with or close to. Givers in the smile $(M=1.90, S D=2.43)$ and happy $(M=1.98, S D=$ 2.10) goal conditions reported knowing their friends for an equal number of years, $t(58)=-0.15$, $p=.88$. An analysis of the perceived closeness index revealed that givers in the smile $(M=5.50$, $S D=1.24)$ and happy $(M=5.22, S D=1.49)$ goal conditions also felt equally close to their friends, $t(58)=0.78, p=.44$. Similarly, receivers in the smile $(M=1.87, S D=2.28)$ and happy $(M=1.98, S D=2.11)$ goal conditions reported knowing their friends for an equal number of years, $t(58)=-0.21, p=.84$, and those in the smile $(M=5.47, S D=1.22)$ and happy $(M=5.29$, $S D=1.42)$ goal conditions also felt equally close to their friends, $t(58)=0.51, p=.61$.

Perceived act size. We also examined whether givers in the smile (versus happy) goal condition perceived the act that they performed as being of a different size or scale. An independent samples t-test revealed that givers in the smile $(M=2.68, S D=1.30)$ and happy $(M$ $=3.07, S D=1.65$ ) goal conditions felt they performed equally-sized acts, $t(58)=-1.03, p=.31$.

Perceptions of the assigned goal. Givers' reports of their initial perceptions of and expectations regarding their assigned goal, were analyzed using several (separate) independent samples t-tests. Results showed that givers in the smile $(M=5.94, S D=0.77)$ and happy $(M=$ 
$6.07, S D=0.96$ ) goal conditions reported that they had initially thought they would be equally able to accomplish their assigned goal, $t(58)=-0.60, p=.55$. Givers in the smile $(M=5.52, S D=$ $0.68)$ and happy $(M=5.69, S D=1.04)$ goal conditions also reported they had possessed equally strong expectations that they would successfully accomplish their assigned goal, $t(58)=-0.77, p$ $=.44$. Finally, givers in the smile $(M=3.74, S D=1.71)$ and happy $(M=3.83, S D=1.47)$ goal conditions reported that they had initially thought their assigned goal would be equally challenging to accomplish, $t(58)=-0.21, p=.84$. Thus, givers' reports of their initial perceptions of their assigned goal did not differ across the smile and happy goal conditions.

Expectation-reality gap. Having demonstrated that none of the above mentioned constructs varied as a function of prosocial goal condition, we tested our proposed mechanism with an independent samples t-test on the measure of the perceived gap between expectations and reality. This analysis revealed the predicted effect of prosocial goal condition, $t(58)=3.16, p$ $<.01, d=.82$. Givers in the smile goal condition $(M=6.26, S D=1.06)$ perceived that the outcome of their act better met their expectations for accomplishing the assigned prosocial goal than did givers in the happy goal condition $(M=5.34$, $S D=1.17)$. Moreover, correlation analyses showed that, across conditions, having a more specific goal in mind when performing the act was associated with the act outcome better meeting one's expectations, $r=.71, p<.01$, and perceiving one's goal as more abstract (versus concrete) was associated with the outcome of the act meeting one's expectations to a lesser extent, $r=-.45, p<.01$.

Giver personal happiness. An independent samples t-test revealed the predicted effect of prosocial goal condition, $t(58)=2.90, p=.01, d=.75$. After performing an act to accomplish their assigned goal (during the break), givers in the smile goal condition $(M=5.94, S D=1.44)$ felt happier than did givers in the happy goal condition $(M=4.86, S D=1.43)$. Further, 
correlation analyses supported our account of this effect by showing that, across conditions, greater perceived goal specificity was associated with greater personal happiness, $r=.58, p<$ .01 , and perceiving the assigned goal as more abstract was associated with less personal happiness, $r=-.37, p<.01$.

Next, a mediation analysis was conducted. We employed nonparametric bootstrapping procedures to calculate this indirect effect using PROCESS in SPSS (Hayes, 2013).

Bootstrapping provided a confidence interval (CI) around the indirect effect of the independent variable (goal condition) on the dependent variable (personal happiness) via the mediator (expectation-reality gap size). The results showed that those in the smile (versus happy) goal condition did indeed feel happier as a result of their smaller expectation-reality gaps (i.e., because the outcome of their acts better met their expectations of accomplishing their goal; $\beta=$ .78; 95\% CI of indirect effect: LLCI = 0.27 and ULCI $=1.42$ ).

Type of act performed. Although givers in both conditions were given the same amount of time to perform their acts and performed their acts in the same location (and thus had the same resources at their disposal), it could still be argued that the observed effect of goal condition on personal happiness was due to a difference in the types of acts performed by givers in the two goal conditions. To address this alternative account, givers' descriptions of their acts were coded by two condition- and hypothesis-blind research assistants using a non-mutually exclusive system. The list of possible act types was developed by the researchers prior to running the experiment, and the act type categories $(0=n o, 1=y e s)$ that received at least one response were: told their friend an amusing story or joke; discussed a future event with their friend; gossiped about a mutual acquaintance with their friend; playfully teased their friend; discussed a past event with their friend; drew their friend a picture; engaged in physical contact with their friend. 
All descriptions were coded by at least one research assistant. Forty percent of descriptions were coded by both research assistants and the percent agreement between the two was 92\% (inter-rater reliability for all category ratings: ICCs $>.89$, ps $<.01$ ). Chi-square tests then examined the significance of differences in act type frequencies between the smile and happy goal conditions (see Table 3). The results revealed that the types of acts performed did not significantly differ across conditions, $\chi^{2} s<1.00$, $p s>.32$, indicating the observed effects were not driven by the givers in the two conditions performing different types of acts.

Receiver personal happiness. Testing whether framing givers’ assigned prosocial goals at different levels of abstraction impacted receivers' happiness, an independent samples t-test on receivers' reports of their personal happiness (after the three minute break) was conducted. After the break, receivers in the smile $(M=5.81, S D=0.95)$ and happy $(M=6.03, S D=0.87)$ goal conditions felt equally happy, $t(58)=-0.97, p=.34$. Furthermore, receivers in the smile $(M=$ $5.94, S D=1.06)$ and happy $(M=5.86, S D=1.36)$ goal conditions reported smiling just as much during their three-minute interaction with their friend, $t(58)=0.23, p=.82$, and receivers in the smile $(M=6.13, S D=0.89)$ and happy $(M=5.83, S D=1.26)$ goal conditions also reported feeling equally happy during their interaction with their friend, $t(1,58)=1.08, p=.28$.

Discussion. Experiment 3 replicated the main results of the first two experiments in a laboratory setting: Performing an act of kindness in pursuit of a more concretely- (versus abstractly-) framed prosocial goal resulted in greater happiness for giver. Experiment 3 also provided further evidence for the proposed mechanism: A mediation analysis again demonstrated that the boost in personal happiness experienced by givers who possessed the more concretelyframed prosocial goal of making someone smile (versus the more abstractly-framed goal of 
making someone happy) was driven by the actual outcome of their attempts to accomplish their prosocial goal better meeting their expectations.

Experiment 3 also provided evidence that serves to address several alternative accounts for the observation that a giver's personal happiness was greater after attempting to make someone else smile (versus happy). First, receivers in both conditions were all friends with their respective givers and neither the perceived closeness of giver-receiver friendships nor the length of these friendships differed across conditions. Thus, the greater personal happiness experienced by givers in the smile (versus happy) goal condition was not a result of givers in the two conditions targeting different types of recipients. Second, givers in both conditions perceived that the acts of kindness they performed were equal in size. Thus, the greater personal happiness experienced by givers in the smile (versus happy) goal condition was also not due to givers in the smile (versus happy) goal condition perceiving that they had performed a smaller or bigger act of kindness. Third, the personal happiness effect was also not due to givers in the smile (versus happy) goal condition actually making their recipients happier: Receivers in both conditions were left equally happy after the three minute interaction with their givers and also reported that they had felt equally happy (and smiled just as much) during their interaction with their friend.

Last, the results of Experiment 3 suggested that people may not make correct predictions about pursuing an abstractly-framed (versus concretely-framed) prosocial goal. Specifically, when asked about their initial predictions and expectations about their assigned goal, givers in the smile and happy goal conditions reported that they had initially perceived their assigned goal as equally challenging, had equally strong expectations of succeeding at their assigned goal, and had believed just as strongly that they would be able to accomplish their assigned goal. Given that those who pursued the more abstractly-framed (versus concretely-framed) prosocial goal 
subsequently experienced a larger expectation-reality gap, these results suggest that people may have a general misunderstanding of the achievability of goals framed in more abstract (versus concrete) terms.

\section{Experiment 4}

Experiments 1-3 were focused on one particular abstractly-framed prosocial goal— making someone happy_and a more concretely-framed, but functionally similar, version of this prosocial goal—making someone smile. But would our effects on givers’ expectation-reality gap size and personal happiness occur with other abstractly-framed versus concretely-framed (but functionally similar) prosocial goals? A primary goal of Experiment 4 was therefore to test whether the results of the prior experiments generalize to other prosocial goals by examining a different pair of functionally similar prosocial goals that varied in their level of abstraction.

Moreover, in the prior experiments, givers’ prosocial goals (and their corresponding acts) were designed to benefit an individual. Of course, not all prosocial actions are designed to benefit just one other person—some are designed to benefit many other people or even society at large. Thus, a second goal of Experiment 4 was to test whether our effects would hold when givers performed acts designed to benefit more than just one other person, by investigating a pair of prosocial goals designed to benefit society as a whole.

Another change made for this experiment was the time at which participants' initial expectations regarding their assigned goal were assessed. In Experiment 3, participants reported their initial expectations after they performed their acts of kindness. As a result, one may question whether these initial predictions would have been different had they been measured prior to when participants performed their acts. Thus, a third goal of Experiment 4 was to address 
these concerns by measuring participants’ initial goal expectations just after participants received their assigned goal (and prior to when they performed their act).

Finally, it could be argued that the effects observed in Experiments 1-3 were due not to the different goal abstractness between conditions, but instead to a difference between the two goal conditions in the extent to which givers were a) influenced by emotion contagion (e.g., perhaps when givers focus on making someone smile they feel happier because they become more susceptible to catching the emotions of their act recipients) or b) required to access another person's internal state (e.g., perhaps when givers focus on making someone happy they feel less happy because they have to try harder to access the minds of recipients). Thus, a fourth goal of Experiment 4 was to address these alternative explanations by investigating a pair of prosocial goals that were unlikely to result in emotion contagion effects and that did not ask givers to access another person’s internal state: an abstract environmental prosocial goal—support environmental sustainability_and a more concretely-framed (but functionally similar) version of this prosocial goal-increase the amount of materials or resources that are recycled or reused.

\section{Method}

Participants and design. Seventy people from a national survey pool (70\% female, 30\% male; $\left.M_{\text {Age }}=34.89, S D_{\text {Age }}=9.15\right)$ participated in exchange for a $\$ 5$ Amazon.com gift card. The experiment used a 2 cell (Prosocial Goal: Concrete vs. Abstract) between-subjects design.

Procedure. Participants took part in a two-part survey. First, participants randomly assigned to the abstract [concrete] goal condition were told, "During this study, we ask that you pursue the following goal: Support environmental sustainability [Increase the amount of materials or resources that are recycled or reused].” All participants were then informed that they 
would have 24 hours in which to perform an act designed to accomplish their goal, and that they would complete a follow-up survey after this 24 hour period.

Immediately after receiving their assigned goal and task, participants responded to several items that assessed their predictions about their prosocial goal. These items included measures paralleling the task prediction items used in Experiment 3 as well as the following additional items: "How prosocial in nature do you think this goal is?” $(1=$ not at all, 7 = very), "How high are your expectations that an act you performed would accomplish this goal?" $(1=$ not at all, 7 = very), "How possible do you think it is to accomplish this goal?" $(1=$ not at all, 7 = very $)$, and "How high are your expectations of achieving this goal?” ( $1=$ not at all, 7 = very $)$.

One day later, participants received the follow-up survey, which asked them to briefly describe the act they performed and respond to several filler items about the assigned task. Embedded in these filler questions were several key items. To measure personal happiness, participants responded to the following item with regard to the act they had performed: “To what degree do you feel you created happiness in your own life?” $(1=$ not at all, 7 = very much). To measure others' feelings of happiness, participants responded to the following item, with regard to the act they had performed: "To what degree do you feel you created happiness in the lives of others?” (1 = not at all, 7 = very much). Participants also reported the perceived size of their expectation-reality gaps (as in Experiment 2), their perceptions of their act's impact ("How impactful was the effect your act had?”; $1=$ not at all, $7=$ very), the size of the effect of their act (“How big was the effect your act had?”; 1 = not at all, 7 = very), the authenticity of their act ("How authentic did your act feel?" $1=$ not at all, $7=$ very), the size of the act they performed ("To what extent do you feel that the act you performed was something small or something 
big?”; 1 = very small, 7 = very big), and how enjoyable it was to pursue their assigned goal (“To what extent did you enjoy pursuing your assigned goal?”; 1 = not at all, 7 = very much).

Participants also reported their perceptions of the level of abstraction at which their assigned prosocial goal was framed: "How concrete versus abstract is the prosocial environmental goal you were asked to pursue?” $(1=$ very concrete, 7 = very abstract $)$. We also assessed whether the two goals were perceived as functionally similar using the following two items ( 1 = not at all; 7 = very much): "Thinking about the act you performed, to what extent do you think that the function or purpose of this act could be framed as 'supporting environmental sustainability’?” and “Thinking about the act you performed, to what extent do you think that the function or purpose of this act could be framed as 'increasing the amount of materials or resources that are reused or recycled'?”

\section{Results and Discussion}

Manipulation checks. An independent samples t-test conducted on participants’ ratings of the perceived concreteness (versus abstractness) of their prosocial goal confirmed that the level of goal abstraction manipulation was successful. Those in the abstract condition $(M=4.46$, $S D=1.48$ ) perceived their assigned goal as being more abstract (versus concrete) than did those in the concrete condition $(M=3.37, S D=1.66), t(68)=2.88, p=.01, d=.69$.

Two additional independent samples t-tests supported the assertion that the two prosocial goals we used were perceived as functionally similar. Those in the abstract goal condition $(M=$ $5.97, S D=1.25)$ and those in the concrete goal condition $(M=6.11, S D=1.11)$ thought that the function of the act they performed could be framed as "supporting environmental sustainability" to an equal extent, $t(68)=-0.51, p=.61$. Those in the abstract $(M=5.91, S D=1.42)$ and concrete $(M=5.83, S D=1.25)$ goal conditions also thought that the function of the act they 
performed could be framed as "increasing the amount of materials or resources that are recycled or reused" to an equal extent, $t(68)=0.27, p=.79$.

Perceptions of the assigned goal. Participants' initial perceptions of and expectations regarding their assigned goal (which were measured right after they received their assigned goal and task), were analyzed using a series of independent samples t-tests. Those in the concrete goal $(M=5.66, S D=1.08)$ and abstract goal $(M=5.43, S D=1.54)$ conditions perceived their assigned goals as being equally prosocial in nature, $t(68)=-0.72, p=.47$. They also had equally high expectations that an act they performed would accomplish their assigned goal $\left(M_{\text {Abstract }}=\right.$ 5.60, $\left.S D_{\text {Abstract }}=1.31 ; M_{\text {Concrete }}=5.86, S D_{\text {Concrete }}=1.00\right), t(68)=-0.92, p=.36$, thought they would be able to accomplish their assigned goal to an equally great extent $\left(M_{\text {Abstract }}=5.97\right.$, $\left.S D_{\text {Abstract }}=1.07 ; M_{\text {Concrete }}=6.03, S D_{\text {Concrete }}=0.89\right), t(68)=-0.24, p=.81$, thought they would successfully accomplish their assigned goal to an equally great extent $\left(M_{\text {Abstract }}=5.71, S D_{\text {Abstract }}\right.$ $\left.=1.38 ; M_{\text {Concrete }}=6.06, S D_{\text {Concrete }}=0.94\right), t(68)=-1.21, p=.23$, thought accomplishing their assigned goal would be equally challenging $\left(M_{\text {Abstract }}=3.37, S D_{\text {Abstract }}=1.85 ; M_{\text {Concrete }}=3.54\right.$, $\left.S D_{\text {Concrete }}=1.93\right), t(68)=-0.38, p=.71$, thought it was equally possible to accomplish their assigned goal $\left(M_{\text {Abstract }}=5.83, S D_{\text {Abstract }}=1.46 ; M_{\text {Concrete }}=6.03, S D_{\text {Concrete }}=0.92\right), t(68)=-0.68$, $p=.50$, and had equally high expectations of achieving their assigned goal $\left(M_{\text {Abstract }}=5.74\right.$, $\left.S D_{\text {Abstract }}=1.36 ; M_{\text {Concrete }}=5.83, S D_{\text {Concrete }}=1.07\right), t(68)=-0.29, p=.77$.

Perceptions of the act. An independent samples t-test examined whether those in the concrete (versus abstract) goal condition thought their acts were of a different size or scale. The results revealed that those in the concrete $(M=3.09, S D=1.72)$ and abstract $(M=3.17, S D=$ 1.60) goal conditions felt they performed equally-sized acts, $t(68)=0.22, p=.83$. We similarly analyzed participants’ perceptions of the overall effect their act had and found that those in the 
abstract and concrete goal conditions felt that their act was equally impactful $\left(M_{\text {Abstract }}=4.49\right.$, $\left.S D_{\text {Abstract }}=1.46 ; M_{\text {Concrete }}=4.54, S D_{\text {Concrete }}=1.60\right), t(68)=-0.16, p=.88$, and that the size of the effect that their act had was equally sized $\left(M_{\text {Abstract }}=3.94, S D_{\text {Abstract }}=1.68 ; M_{\text {Concrete }}=4.14\right.$, $\left.S D_{\text {Concrete }}=1.63\right), t(68)=-0.51, p=.62$.

To assess whether those in the concrete (versus abstract) goal condition perceived that the act they performed differentially impacted others’ happiness, an independent samples t-test was conducted on participants' reports of the happiness they felt they created in the lives of others. Those in the concrete $(M=4.91, S D=1.56)$ and abstract $(M=4.71, S D=1.45)$ goal conditions felt their act created an equal amount of happiness in others' lives, $t(68)=-0.56, p=.58$.

Participants’ perceptions of how it felt to perform their act and pursue their goal were also analyzed using two (separate) independent samples t-tests. Those in the abstract and concrete goal conditions reported that their acts felt equally authentic $\left(M_{\text {Abstract }}=5.34, S D_{\text {Abstract }}\right.$ $\left.=1.63 ; M_{\text {Concrete }}=5.46, S D_{\text {Concrete }}=1.65\right), t(68)=-0.29, p=.77$, and they equally enjoyed pursuing their assigned goals $\left(M_{\text {Abstract }}=5.03, S D_{\text {Abstract }}=1.34 ; M_{\text {Concrete }}=5.11, S D_{\text {Concrete }}=\right.$ 1.79), $t(68)=-0.23, p=.82$.

Expectation-reality gap. Having demonstrated that the above constructs did not vary as a function of prosocial goal condition, we tested our proposed mechanism: An independent samples t-test was conducted on the measure of the perceived gap between participants' expectations and reality. This analysis revealed the predicted effect of prosocial goal condition, $t(68)=-3.14, p<.01, d=.75$. Those in the concrete goal condition $(M=5.71, S D=1.15)$ perceived that the outcome of their act better met their expectations for accomplishing the assigned prosocial goal than did those in the abstract goal condition $(M=4.74, S D=1.42)$. Correlational analyses further showed that, across conditions, perceiving one's prosocial goal as 
more abstract (versus concrete) was associated with the act outcome meeting one's expectations to a lesser extent, $r=-.30, p<.01$.

Giver personal happiness. The results of an independent samples t-test on the personal happiness measure revealed the predicted effect of prosocial goal condition. Participants in the concrete goal condition $(M=4.80, S D=1.75)$ felt their act created more personal happiness than did those in the abstract goal condition $(M=3.89, S D=1.86), t(68)=-2.12, p=.04, d=.50$.

Next, a mediation analysis was conducted. We employed nonparametric bootstrapping procedures to calculate this indirect effect using PROCESS in SPSS (Hayes, 2013). Bootstrapping provided a confidence interval (CI) around the indirect effect of the independent variable (goal condition) on the dependent variable (personal happiness) via the mediator (expectation-reality gap size). The results showed that those in the concrete goal (versus abstract goal) condition felt they created more personal happiness as a result of their smaller expectationreality gaps (i.e., because the outcome of their acts better met their expectations of accomplishing their goal; $\beta=.70 ; 95 \% \mathrm{CI}$ of indirect effect: $\mathrm{LLCI}=0.30$ and ULCI $=1.23$ ).

Type of act performed. To examine whether the observed effects could be explained by differences in the types of acts performed by those in the two goal conditions, participants' act descriptions were coded by two condition- and hypothesis-blind research assistants using a nonmutually exclusive system. The list of possible act types was developed by the researchers prior to running the experiment, and the act type categories $(0=$ no, $1=y e s)$ that received at least one response were: recycled or reused something; created or enhanced a recycling receptacle; gardened or composted; reduced emissions; reduced energy consumption; collected trash/nonrecyclable waste; educated someone about environmentally-friendly behaviors; reduced or prevented the creation of non-recyclable waste; other. 
All descriptions were coded by at least one research assistant. Forty percent of descriptions were coded by both research assistants and the percent agreement between the two was $96 \%$ (inter-rater reliability for all category ratings: ICCs $>.90$, ps $<.01$ ). Chi-square tests then examined the significance of differences in act type frequencies between the concrete and abstract conditions (see Table 4). The results revealed that the types of acts performed did not significantly differ across conditions, $\chi^{2} s<2.06$, $p s>.15$, indicating the observed effects were not driven by those in the two conditions performing different types of acts.

Discussion. Experiment 4 replicated the main results of the prior experiments using a different pair of abstractly- (versus concretely-) framed, prosocial goals: Performing an act in pursuit of the more concretely-framed prosocial goal of increasing the amount of resources or materials that are recycled or reused created greater giver happiness than did performing an act in pursuit of the more abstractly-framed (but functionally similar) prosocial goal of supporting environmental sustainability. A mediational analysis once again demonstrated that the boost in personal happiness experienced by those who possessed the more concretely- (versus abstractly-) framed prosocial goal was driven by their perceptions that the actual outcome of their acts better met their expectations for accomplishing their goals. Taken together, these results demonstrate that the effects observed in the prior experiments generalize to other prosocial goals, and are not specific to the goals of making someone smile versus happy. Moreover, whereas givers in the prior experiments pursued prosocial goals designed to benefit an individual, givers in Experiment 4 pursued prosocial goals designed to benefit society as a whole. Thus, the effects observed in the prior experiments also generalize to prosocial goals that target society at large. Experiment 4 also helped address several alternative accounts. First, the results revealed that the greater personal happiness experienced by givers in the concrete (versus abstract) goal 
condition was not a result of these givers having different initial perceptions of or predictions about their assigned prosocial goal. Second, the greater personal happiness experienced by givers in the concrete (versus abstract) goal condition could also not be explained by differences in perceived act size, act authenticity, act impact, act effect size, or the act's ability to create happiness in the lives of others. Third, neither of the prosocial goals used in this experiment required givers to assess the internal state of another person. Therefore, whereas it could be argued that the observed differences in personal happiness in Experiments 1-3 were due to differences in the extent to which givers were asked to try and assess their recipients' internal states (as givers in the happy condition were required to assess the internal state of their recipient more so than were givers in the smile condition), this alternative account cannot explain the results obtained in Experiment 4.

Finally, because the prosocial goals used in Experiment 4 were designed to benefit Earth—and thus society as a whole—neither of the prosocial goals used in this experiment required that givers directly interact with another person (i.e., in order for givers to perform a goal-directed act they did not have to interact with a human recipient). Thus, it is unlikely that the effects in Experiment 4 can be explained by a difference in the amount of emotion contagion experienced by givers in the concrete (versus abstract) goal condition.

\section{Experiment 5}

Experiment 5 had three main goals. The first was to offer further evidence that emotion contagion is unlikely to account for why an act performed in pursuit of a concretely- (versus abstractly-) framed prosocial goal leads to greater giver happiness. To accomplish this aim, Experiment 5 utilized a laboratory setting to ensure that no givers in either condition came in contact with the recipients of their acts. 
The second goal was to more definitively address the possibility that the observed effect of prosocial goal condition on personal happiness was due to differences in the types of acts performed by those in the two goal conditions. Thus, in Experiment 5, all givers were provided with the same tools with which to accomplish their differently-framed prosocial goals and all givers performed the same act of kindness in pursuit of their differently-framed goals. So, although the level of abstraction at which givers' assigned goals were framed differed across conditions, the acts of kindness performed by the givers did not.

The third goal was to further generalize the results of the prior experiments by examining yet another pair of functionally similar prosocial goals, from a different prosocial domain, that varied only in their level of abstraction. Moreover, because the prosocial goals in the prior experiments were designed to benefit either an individual (i.e., benefit only one other person; as in Experiments 1-3) or society as a whole (i.e., benefit everyone; as in Experiment 4), the prosocial goals used in Experiment 5 lie between these two extremes (i.e., they benefit multiple people or a group). Specifically, Experiment 5 focused on the abstractly-framed prosocial goal to "give those who need bone marrow transplants greater hope” and a more concretely-framed (but functionally similar) version of this prosocial goal (i.e., "give those who need bone marrow transplants a better chance of finding a donor”).

\section{Method}

Participants and design. Ninety two university students (64\% female, 36\% male; $M_{\text {Age }}$ $=21.96, S D_{\text {Age }}=4.83$ ) participated in exchange for $\$ 10$. The experiment used a 2 cell (Prosocial Goal: Concrete vs. Abstract) between-subjects design.

Procedure. Participants completed two surveys. Shortly after arriving at the laboratory, participants were brought to a private experimental room. They completed the first survey, where 
they received some brief background information about patients in need of life-saving bone marrow transplants (including that many of these patients cannot find a suitable donor) after which they were asked to perform an act of kindness for these patients, keeping one of two prosocial goals in mind. Participants randomly assigned to the abstract [concrete] goal condition were told, "During this study, we would like you to pursue the following goal: Give those who need bone marrow transplants greater hope [Give those who need bone marrow transplants a better chance of finding a donor].” After receiving their assigned prosocial goal, participants responded to several items that asked about their initial predictions about their goal (i.e., how they perceived their assigned prosocial goal). These items paralleled those used in Experiment 4.

Then, participants were told there would be a fifteen-minute break before they completed the second survey, and that, during this break, they would pursue their assigned prosocial goal by performing an act of kindness for those who need bone marrow transplants. They were asked to prepare 10 bone marrow donor recruitment flyers to be mailed to people who meet the requirements for registering as a potential bone marrow donor. Participants were also informed that they would be provided with all the tools they would need to perform this task (i.e., a stack of envelopes, a stack of flyers, a mailing list sheet with the names and addresses of people who meet the requirements for registering as bone marrow donors, and a writing implement). Participants also received instructions for preparing the 10 flyers for mailing: grab an envelope, write the name and address of the person on the mailing list on the front/center of the envelope, write the provided return address in the upper left-hand corner of the envelope, grab a flyer, fold it, place it into the envelope, and seal the envelope. After receiving the task instructions, participants were led from their private room and placed in the "break room," where all of the tools they needed to perform their act (as well as a copy of the task instructions) were waiting for 
them. Next, all participants performed the same act of kindness (i.e., preparing 10 bone marrow donor recruitment flyers for mailing) for those who need bone marrow transplants.

Fifteen minutes later, participants were escorted back to their private room to complete the second survey. Embedded in several filler questions were our key measures of personal happiness (“How happy are you right now?”; 1 = not at all, 7 = extremely), others' feelings of happiness ("To what degree do you feel you created happiness in the lives of those who need bone marrow transplants?”; 1 = not at all, 7 = very much), and the perceived size of participants' expectation-reality gaps (measured as in Experiment 2). Using measures paralleling those in Experiment 4, participants also reported their perceptions of the impact of their act, the size of the effect of their act, the authenticity of their act, the size of their act, and much they enjoyed pursuing their assigned goal. Participants also responded to a 2-item perceived closeness index (1 $=$ not at all, 7 = extremely; $\alpha=0.93)$ : "How close do you feel you are to those who are in need of a bone marrow transplant?" and "How personally connected are you to patients who are in need of a bone marrow transplant?”

As a manipulation check, participants also reported their perceptions of the level of abstraction at which their assigned prosocial goal was framed (as in Experiment 4). Last, as an additional check, two items assessed whether the goals were perceived as functionally similar (1 = not at all; 7 = very much): "Thinking about the act you performed, to what extent do you think that the function or purpose of this act could be framed as 'giving those who need bone marrow transplants greater hope??” and "Thinking about the act you performed, to what extent do you think that the function or purpose of this act could be framed as 'giving those who need bone marrow transplants a better chance of finding a donor’?”

\section{Results and Discussion}


Manipulation checks. An independent samples t-test confirmed that the level of goal abstraction manipulation was successful. Those in the abstract goal condition $(M=3.13, S D=$ 1.26) perceived their assigned goal as being more abstract (versus concrete) than did those in the concrete goal condition $(M=2.50, S D=1.38), t(90)=2.29, p=.02, d=.48$.

Two additional independent samples t-tests supported the assertion that the two prosocial goals we used were perceived as functionally similar. Those in the abstract $(M=5.37, S D=$ 1.34) and concrete $(M=5.24, S D=1.54)$ goal conditions thought that the function of the act they performed could be framed as "giving those who need bone marrow transplants greater hope” to an equal extent, $t(90)=0.43, p=.67$. Those in the abstract $(M=5.63, S D=1.44)$ and concrete $(M=5.89, S D=1.12)$ goal conditions also thought that the function of the act of kindness that they performed could be framed as "giving those who need bone marrow transplants a better chance of finding a donor” to an equal extent, $t(90)=-0.97, p=.33$.

Perceptions of the assigned goal. Participants' initial perceptions of and expectations regarding their assigned goal (which were measured right after they received their assigned goal), were analyzed using several independent samples t-tests. Those in the concrete $(M=6.09$, $S D=0.96)$ and abstract $(M=5.96, S D=0.99)$ conditions perceived their assigned goals as equally prosocial in nature, $t(90)=-0.64, p=.52$. Those in the abstract and concrete conditions also had equally high expectations that an act they performed would accomplish their assigned goal $\left(M_{\text {Abstract }}=4.41, S D_{\text {Abstract }}=1.17 ; M_{\text {Concrete }}=4.80, S D_{\text {Concrete }}=1.33\right), t(90)=-1.50, p=.14$, thought they would be able to accomplish their assigned goal to an equally great extent $\left(M_{\text {Abstract }}\right.$ $\left.=4.30, S D_{\text {Abstract }}=1.38 ; M_{\text {Concrete }}=4.63, S D_{\text {Concrete }}=1.44\right), t(90)=-1.11, p=.27$, thought they would successfully accomplish their assigned goal to an equally great extent $\left(M_{\text {Abstract }}=4.28\right.$, $\left.S D_{\text {Abstract }}=1.28 ; M_{\text {Concrete }}=4.43, S D_{\text {Concrete }}=1.34\right), t(90)=-0.56, p=.58$, thought 
accomplishing their assigned goal would be equally challenging $\left(M_{\text {Abstract }}=5.54, S D_{\text {Abstract }}=\right.$ 1.29; $\left.M_{\text {Concrete }}=5.80, S D_{\text {Concrete }}=1.17\right), t(90)=1.02, p=.31$, thought it was equally possible to accomplish their assigned goal $\left(M_{\text {Abstract }}=5.85, S D_{\text {Abstract }}=0.99 ; M_{\text {Concrete }}=6.04, S D_{\text {Concrete }}=\right.$ 1.17), $t(90)=-0.87, p=.39$, and had equally high expectations of achieving their assigned goal $\left(M_{\text {Abstract }}=4.41, S D_{\text {Abstract }}=1.27 ; M_{\text {Concrete }}=4.59, S D_{\text {Concrete }}=1.53\right), t(90)=-0.59, p=.55$.

Perceptions of the act. We examined whether those in the concrete (versus abstract) goal condition thought the act they performed was of a different size or scale. The results of an independent samples t-test on participants' reports of perceived act size revealed those in the concrete $(M=2.70, S D=1.43)$ and abstract $(M=2.41, S D=1.15)$ conditions felt they performed equally-sized acts, $t(90)=-1.05, p=.30$. We analyzed participants' perceptions of the overall effect of their act and found that those both conditions felt their act was equally impactful $\left(M_{\text {Abstract }}=3.72, S D_{\text {Abstract }}=1.46 ; M_{\text {Concrete }}=3.96, S D_{\text {Concrete }}=1.50\right), t(90)=-0.78, p=.44$, and that it had an equally-sized effect $\left(M_{\text {Abstract }}=3.57, S D_{\text {Abstract }}=1.50 ; M_{\text {Concrete }}=3.48, S D_{\text {Concrete }}=\right.$ 1.52), $t(90)=0.28, p=.78$.

Participants' perceptions of how it felt to perform the act and pursue their goal were also analyzed using two (separate) independent samples t-tests. Those in the abstract and concrete goal conditions reported that their act felt equally authentic $\left(M_{\text {Abstract }}=4.20, S D_{\text {Abstract }}=1.60\right.$; $\left.M_{\text {Concrete }}=4.28, S D_{\text {Concrete }}=1.64\right), t(90)=-0.26, p=.80$, and they equally enjoyed pursuing their goals $\left(M_{\text {Abstract }}=5.20, S D_{\text {Abstract }}=1.07 ; M_{\text {Concrete }}=5.33, S D_{\text {Concrete }}=1.12\right), t(90)=-0.57, p=.57$.

Perceptions of recipients. An independent samples t-test was conducted on participants’ reports of the happiness they felt they created in the lives of those who are in need of bone marrow transplants. Those in the concrete $(M=4.41, S D=1.34)$ and abstract $(M=4.24, S D=$ 1.45) goal conditions felt their act created an equal amount of happiness in bone marrow 
patients' lives, $t(90)=-0.60, p=.55$. Ratings concerning givers' perceptions of how close they felt (after performing their act of kindness) to patients in need of a bone marrow transplant were also analyzed. An independent samples t-test on the perceived closeness index revealed that givers in the concrete $(M=3.72, S D=1.56)$ and abstract $(M=3.43, S D=1.55)$ goal conditions felt equally close to patients in need of bone marrow transplants, $t(90)=-0.87, p=.39$.

Expectation-reality gap. Having demonstrated the above constructs did not vary as a function of prosocial goal condition, we tested the proposed mechanism: An independent samples t-test was conducted on the measure of participants’ expectation-reality gaps. This analysis revealed the predicted effect of prosocial goal condition, $t(90)=-2.84, p=.01, d=.60$. Those in the concrete condition $(M=4.61, S D=1.20)$ perceived that the outcome of their act better met their expectations for accomplishing the assigned prosocial goal than did those in the abstract condition $(M=3.78, S D=1.56)$. Correlation analyses further showed that, across conditions, perceiving one’s prosocial goal as more abstract (versus concrete) was associated with the outcome of the act meeting one's expectations to a lesser extent, $r=-.34, p<.01$.

Giver personal happiness. An independent samples t-test on the measure of personal happiness revealed the predicted effect of prosocial goal condition. Those in the concrete condition $(M=4.63, S D=1.34)$ felt happier after performing the act of kindness than did those in the abstract condition $(M=3.98, S D=1.29), t(90)=-2.38, p=.02, d=.49$.

Next, a mediation analysis was conducted. We employed nonparametric bootstrapping procedures to calculate this indirect effect using PROCESS in SPSS (Hayes, 2013). Bootstrapping provided a confidence interval (CI) around the indirect effect of the independent variable (goal condition) on the dependent variable (happiness) via the mediator (expectationreality gap size). The results showed that those in the concrete (versus abstract) goal condition 
felt happier as a result of their smaller expectation-reality gaps (i.e., because their act's outcome better met their expectations of accomplishing their goal; $\beta=.23 ; 95 \% \mathrm{CI}$ of indirect effect: $\mathrm{LLCI}=0.06$ and ULCI $=0.59)$.

Discussion. Experiment 5 replicated the main results of the prior experiments using yet another pair of functionally similar, but abstractly- (versus concretely-) framed, prosocial goals: Performing an act of kindness in pursuit of the more concretely-framed goal of giving those who need bone marrow transplants a better chance of finding a donor resulted in greater happiness for givers than did performing an act of kindness in pursuit of the more abstractly-framed (but functionally similar) goal of giving those who need bone marrow transplants greater hope. Moreover, a mediational analysis demonstrated once more that the boost in personal happiness experienced by those with the more concretely- (versus abstractly-) framed prosocial goal was driven by their perceptions that the outcome of their goal-directed act better met their expectations of accomplishing their prosocial goal. Although this paradigm again required some assessment of others' internal states (as in Experiment 1-3 but not Experiment 4), these results provide further evidence that the effects observed in the prior experiments generalize to other prosocial goals and acts. Moreover, whereas givers in the prior experiments pursued prosocial goals designed to benefit either an individual or society as a whole, givers in Experiment 5 pursued prosocial goals designed to benefit a group. Thus, the predicted effects were obtained regardless of the number of recipients the prosocial goals were designed to benefit.

Experiment 5 also helped address several alternative accounts for the observed personal happiness effect. First, this experiment provided additional evidence that there were no significant differences in participants' initial perceptions of or predictions about their assigned prosocial goals that could account for the observed effects. Second, the results revealed personal 
happiness effect could also not be explained by differences in perceived act size, act authenticity, act impact, act effect size, or the act's ability to create happiness in the lives of those who need bone marrow transplants. Third, no givers in this experiment came into contact with or interacted with the recipients of their act of kindness. Thus, an emotion contagion explanation cannot account for the observed results — as it was not possible for givers in either prosocial goal condition to catch any emotions from (or be influenced by) the recipients of their act. Last, all givers performed the exact same act of kindness using the exact same set of tools. Thus, the greater personal happiness experienced by givers in the concrete goal condition could also not have been due to differences in the goal-directed acts of kindness that givers performed.

\section{Experiment 6}

In Experiments 3-5, participants in the abstract and concrete goal conditions initially believed that they would be equally likely to succeed at and accomplish their prosocial goals. Moreover, people often make inaccurate predictions about how much happiness various things in life will bring (Aknin et al., 2009; Brickman et al., 1978; Buehler \& McFarland, 2001; Dunn et al., 2008). This suggests that people may not correctly predict the link between prosocial goal concreteness and personal happiness. To provide greater insight into this issue, we conducted a final experiment in which we tested the hypothesis (H3) that people will make inaccurate predictions regarding which prosocial goal framing leads to the greatest personal happiness, failing to predict that pursuing a prosocial goal framed in more concrete terms (i.e., make someone smile) would be better for personal happiness than would pursuing a prosocial goal framed more abstractly (i.e., make someone happy).

\section{Method}


Participants and design. Eighty-four people from a national survey pool (62\% female, $38 \%$ male; $M_{\text {Age }}=38.25, S D_{\text {Age }}=13.31$ ) participated in exchange for a $\$ 5$ Amazon.com gift card. A 2 cell (Imagined Prosocial Goal: Smile vs. Happy) between-subjects design was used.

Procedure. Participants were randomly assigned to perform either an act designed to elicit a smile or an act designed to happiness within 24 hours. Participants were then asked to imagine how they would feel in 24 hours (after performing their act), after which they received a copy of the follow-up survey used in Experiment 2. They were then asked to predict how they thought they would answer these questions, including the following item in regards to their act: “To what degree do you feel you created happiness in your own life?” ( 1 = not at all, 7 = very much).” At the end of the study, participants also read descriptions of the prosocial goals used in both conditions (i.e., make someone smile and make someone happy), and rated each (on a scale from 1-100) on the degree to which pursuing that goal would create happiness in their lives.

\section{Results and Discussion}

Predicted personal happiness. The results of an independent samples t-test examined whether those who imagined performing an act designed to make someone else smile predicted that they would create more personal happiness than did those who imagined performing an act designed to make someone else happy. The results revealed that participants in the smile goal condition $(M=5.18, S D=1.52)$ did not correctly predict that they would create more personal happiness than those in the happy goal condition did $(M=5.32, S D=1.38), t(82)=0.45, p=.65$.

A repeated measures ANOVA revealed that participants also rated the experimental condition in which one tries to make someone happy $(M=78.60, S D=19.42)$ as being able to create more personal happiness than the experimental condition in which one tries to make someone smile $(M=74.60, S D=21.19), F(1,82)=8.31, p=.01, \eta_{\mathrm{p}}{ }^{2}=.09$. Importantly, the 
analysis also determined there was no interaction between the ratings of the two described goals and the condition (i.e., smile goal versus happy goal) to which participants were initially randomly assigned, $F(1,82)=0.53, p=.47$, indicating that this pattern of ratings and the belief that pursuing the prosocial goal of making someone happy (versus smile) would create more personal happiness did not differ across conditions.

Discussion. Taken together, the results of Experiment 6 demonstrated that participants appear to be wrong in two ways. When considering only one condition (i.e., one of the prosocial goals), participants incorrectly predicted no difference in personal happiness between the concrete and abstract goals; when considering both conditions (i.e., both goals) simultaneously, they believed that the abstract prosocial goal would lead to greater happiness than the concrete prosocial goal - the exact opposite of the results in the prior experiments. Thus, it seems people do not recognize that acts performed in service of a prosocial goal that is framed concretely (versus abstractly) will more effectively cultivate personal happiness.

\section{General Discussion}

Prior research suggests that one underappreciated means of increasing one’s own happiness is focusing on increasing the happiness of others through prosocial acts. But what kinds of prosocial acts lead to the greatest hedonic returns for givers? Although people’s intuition is that acts performed in pursuit of broad, abstractly-framed prosocial goals—-for example, trying to make someone else happy_create the most happiness for givers, our results suggest that acts performed in pursuit of functionally similar, but more concretely-framed prosocial goals are more effective. Specifically, individuals who performed acts of kindness in pursuit of the prosocial goals of making others smile (versus making others happy; Experiments 1-3), increasing the amount of materials or resources that are recycled or reused (versus 
supporting environmental sustainability; Experiment 4), and giving those in need of bone marrow transplants a better chance of finding a donor (versus giving those in need of bone marrow transplants greater hope; Experiment 5) reported greater personal happiness, an effect that was driven by a smaller gap between one's expectations of achieving the assigned prosocial goal and the actual outcome of the act (Experiments 2-5). Further, participants erroneously believed that efforts to achieve a more abstractly-framed prosocial goal—make others happy— would have a larger (or equal) positive impact on personal happiness than would efforts to achieve a more concretely-framed prosocial goal—make others smile (Experiment 6).

\section{Limitations and Future Research}

Our research focused on the impact of prosocial acts on givers’ self-reported happiness, yet future work is needed to reconcile the current results with prior research (Aquino, McFerran, \& Laven, 2011) demonstrating that merely being exposed to others’ acts of uncommon goodness (versus common benevolence) induces more positive emotions and greater altruism. We demonstrate seemingly opposite results: When a person is the one actually performing the prosocial act (not observing or reading about someone else doing it), more positive consequences ensue when the act's goal is perceived as more concrete (i.e., of a seemingly lesser magnitude). Although framing the goal of a prosocial act in broad, abstract terms may be better for happiness when one is experiencing the act from an outsider's perspective (a potential boundary condition of our effects), we find evidence that framing the goal of a prosocial act in more concrete terms can be better for happiness when one is experiencing the act from an insider's perspective (i.e., when one is actually performing the act oneself). Moreover, our studies focus on reframing functionally similar prosocial goals. Thus, we do not argue that any given concrete prosocial goal is better than any given abstract prosocial goal, but rather that givers are likely to experience 
greater happiness if they framed their prosocial goal in more concrete terms. Relatedly, our account holds that concrete prosocial goals offer more happiness in part because they allow givers to more accurately assess whether they were successful in their goals; of course, concrete prosocial goals could also allow actors to more accurately assess whether they failed at achieving their goals, as well. While this does not appear to be the case in our experiments—our results consistently reveal the hedonic benefits of concrete goals—-future research should explore when concreteness might have more negative effects.

The present research also provides an additional lens into the growing literature on "helper burnout.” Consistent with our account, discrepancies between expectations and reality can be critical factors in determining whether helping leads to giver unhappiness or happiness (Glass \& McKnight, 1996; Schwartz, Meisenhelder, Ma, \& Reed, 2003). When givers expect to change the lives of others through volunteering and other prosocial acts, a perceived failure to accomplish such large goals can lead to frustration and disappointment—making helping a negative rather than a positive influence on givers' happiness. Our results suggest that encouraging givers to re-frame their prosocial goals in more concrete terms might generally reduce helper burnout, which could in turn lead to a more sustainable pattern of prosocial behavior. However, prior research suggests that there may be a special type of giver-an “expert” giver (e.g., nurses) — who responds differently to abstractly-framed prosocial goals. Action identification theory, for example, suggests that those who have mastered the performance of certain tasks are better able to operate at a higher (i.e., more abstract) level identities and actions (Vallacher \& Wegner, 1987). Thus, future research is needed to examine whether the extent to which individuals are "expert" givers in a particular domain will impact the 
relationship between prosocial goal abstraction and personal happiness and whether the source of “helper burnout” differs depending one’s level of expertise.

Our results also suggest several other avenues for future research. First, a deeper examination of actual versus perceived goal attainment would be fruitful. Our results suggest that participants’ acts had a similar effect in both conditions (e.g., recipients were just as happy and smiled just as often in response to givers’ acts), but those in the concrete (versus abstract) goal conditions perceived their acts as more successful. Might there be conditions under which the two goal frames might lead to differences in actual effectiveness? One way to begin addressing this question could be to examine situations in which there is a greater duration between goal onset and the performance of prosocial acts. The present research relied on relatively short durations for performing prosocial acts (i.e., 24 hours or less). But there are many real life goals and goal-directed actions that involve longer temporal gaps. One might expect, for example, that across a longer time frame, an abstract goal framing may have greater impact, as people may perceive that there are more ways in which to pursue the abstractly- (versus concretely-) framed goal. If, for a long-term prosocial goal, a more abstract goal framing does lead one to perform a greater number of (or a greater variety of) prosocial acts over the long run, such a framing may lead to acts that, taken together, are actually more effective at meeting one's expectations of goal success and, thus, are more effective at enhancing personal happiness.

The applied implications of these effects also merit examination. For instance, when gifts are advertised to consumers (e.g., a child's toy is marketed to a mother or a diamond necklace is marketed to a husband), consumers are often given the impression that these gifts are designed to achieve an abstractly-framed prosocial goal—e.g., make the recipient happy. Our results suggest that associating these gifts with abstractly-framed goals may not be the optimal strategy, as 
consumers may not only be left feeling less happy after giving the gift (as a result of the outcome of their gift-giving not as effectively living up to their expectations), but also potentially less satisfied with their purchase. A final avenue for future research is to examine the degree to which the present findings are unique to prosocial goals. Might personal goals follow similar predictions, suggesting a general process applicable to a wide range of goals and goal relevant behaviors? Consider people striving to improve their lives through achieving goals related to their habits (e.g., those in Alcoholics Anonymous). If our results generalize to this domain, they would suggest that framing goals in more concrete terms (e.g., "not drinking today”) versus abstract terms (e.g., "get control over my desire to drink”) would boost their happiness, which could, in turn, further strengthen their resolve.

\section{Conclusion}

People seek to be happy, and one clear path towards happiness is through prosocial behaviors. The current research suggests that such prosocial pursuits can be differentially effective at increasing personal happiness. In particular, prosocial behaviors have a greater positive impact on one's own happiness to the extent that the goals of these acts of kindness are framed in more concrete terms, allowing givers to more accurately calibrate their expectations regarding the outcome of their act and better assess whether their act actually had the desired effect. In short, framing prosocial goals in more concrete (versus abstract) terms-like the goal of making someone smile instead of the goal of making someone happy—wraps a stronger warm glow of happiness around givers. 


\section{References}

Aknin, L. B., Norton, M. I., \& Dunn, E. W. (2009). From wealth to well-being? Money matters, but less than people think. Journal of Positive Psychology, 4, 523-527. doi:10.1080/17439760903271421

Andreoni, J. (1989). Giving with impure altruism: Applications to charity and Ricardian equivalence. Journal of Political Economy, 97, 1447-1458. doi:10.1086/261662

Andreoni, J. (1990). Impure altruism and donations to public goods: A theory of warm-glow giving. The Economic Journal, 100, 464-477. doi:10.2307/2234133

Anik, L., Aknin, L. B., Norton, M. I., \& Dunn, E. W. (2009). Feeling good about giving: The benefits (and costs) of self-interested charitable behavior. In D. M. Oppenheimer \& C. Y. Olivola (Eds.), Experimental approaches to the study of charitable giving (pp. 3-14). New York, NY: Psychology Press.

Aquino, K. McFerran, B., \& Laven, M. (2011). Moral identity and the experience of moral elevation in response to acts of uncommon goodness. Journal of Personality and Social Psychology, 100, 703-718. doi:10.1037/a0022540

Argyle, M. (1999). Causes and correlates of happiness. In D. Kahneman, E. Diener, \& N. Schwarz (Eds.), Well-Being: The foundations of hedonic psychology (pp. 353-373). New York, NY: Russell Sage Foundation.

Brickman, P., \& Campbell, D. T. (1971). Hedonic relativism and planning the good society. In M. H. Appley (Ed.), Adaptation level theory: A symposium (pp. 287-305). New York, NY: Academic Press. 
Brickman, P., Coates, D., \& Janoff-Bulman, R. (1978). Lottery winners and accident victims: Is happiness relative? Journal of Personality and Social Psychology, 36, 917-927. doi:10.1037/0022-3514.36.8.917

Buehler, R., Griffin, D., \& Ross, M. (2002). Inside the planning fallacy: The causes and consequences of optimistic time predictions. In T. D. Gilovich, D. W. Griffin, \& D. Kahneman (Eds.), Heuristics and biases: The psychology of intuitive judgment (pp. 250270). New York, NY: Cambridge University Press.

Carver, C. S., La Voie, L., Kuhl, J., Ganellen, R. J. (1988). Cognitive concomitants of depression: A further examination of the roles of generalization, high standards, and selfcriticism. Journal of Social and Clinical Psychology, 7, 350-365. doi:10.1521/jscp.1988.7.4.350

Carver, C. S., \& Scheier, M. F. (1990). Origins and functions of positive and negative affect: A control-process view. Psychological Review, 97, 19-35. doi:10.1037/0033-295X.97.1.19

Christensen, K., Herskind, A. M., \& Vaupel, J. W. (2006). Why Danes are smug: Comparative study of life satisfaction in the European Union. British Medical Journal, 333, 12891291. doi:10.1136/bmj.39028.665602.55

Davis, W. (1981). A theory of happiness. American Philosophical Quarterly, 18(2), 111-120. Retrieved from http://www.press.uillinois.edu/journals/apq.html

Diener, E. (2000). Subjective well-being: The science of happiness, and a proposal for a national index. American Psychologist, 55, 34-43. doi:10.1037/0003-066X.55.1.34

Diener, E., Suh, E. M., Lucas, R. E., \& Smith, H. L. (1999). Subjective well-being: Three decades of progress. Psychological Bulletin, 125, 276-302. doi:10.1037/00332909.125.2.276 
Diener, E., Suh, E. M., Smith, H., \& Shao, L. (1995). National differences in reported wellbeing: Why do they occur? Social Indicators Research, 34, 7-32. doi:10.1007/BF01078966

Dunn, E. W., Aknin, L. B., \& Norton, M. I. (2008). Spending money on others promotes happiness. Science, 319, 1687-1688. doi:10.1126/science.1150952

Emmons, R. A. (1992). Abstract versus concrete goals: Personal striving level, physical illness, and psychological well-being. Journal of Personality and Social Psychology, 62, 292300. doi:10.1037/0022-3514.62.2.292

Emmons, R. A. (1996). Striving and feeling: Personal goals and subjective well-being. In P. M. Gollwitzer \& J. A. Bargh (Eds.), The psychology of action: Linking cognition and motivation to behavior (pp. 313-337). New York, NY: Guilford Press.

Emmons, R. A., \& Kaiser, H. A. (1996). Goal orientation and emotional well-being: Linking goals and affect through the self. In L. L. Martin \& A. Tesser (Eds.), Striving and feeling: Interactions among goals, affect, and self-regulation (pp. 79-98). Mahwah, NJ: Erlbaum.

Freedman, J. (1978). Happy people: What happiness is, who has it, and why. New York: Harcourt Brace Jovanovich.

Gilbert, D. T. (2006). Stumbling on happiness. New York, NY: Alfred A. Knopf.

Gilbert, D. T., Pinel, E. C., Wilson, T. D., Blumberg, S. J., \& Wheatley, T. (1998). Immune neglect: A source of durability bias in affective forecasting. Journal of Personality and Social Psychology, 75, 617-638. doi:10.1037/0022-3514.75.3.617

Glass, D. C., \& McKnight, J. D. (1996). Perceived control, depressive symptomatology, and professional burnout: A review of the evidence. Psychology and Health, 11, 23-48. doi:10.1080/08870449608401975 
Gollwitzer, P. M. (1993). Goal achievement: The role of intentions. In W. Stroebe \& M.

Hewstone (Eds.), European review of social psychology (Vol. 4, pp. 141-185). New York: Wiley.

Gollwitzer, P. M. (1996). The volitional benefits of planning. In P. M. Gollwitzer \& J. A. Bargh (Eds.), The psychology of action: Linking cognition and motivation to behavior (pp. 287312). New York: Guilford.

Grant, A., \& Sonnentag, S. (2010). Doing good buffers against feeling bad. Prosocial impact compensates for negative task and self-evaluations. Organizational Behavior and Human Decision Processes, 111, 13-22. doi: 10.1016/j.physletb.2003.10.071

Gregg, W. (1972). Several factors affecting graduate student satisfaction. Journal of Higher Education, 43, 483-498. doi:10.2307/1978895

Harbaugh, W. T., Mayr, U., \& Burghart, D. R. (2007). Neural responses to taxation and voluntary giving reveal motives for charitable donations. Science, 316, 1622-1625. doi:10.1126/science.1140738

Hayes, A. F. (2013), An introduction to mediation, moderation, and conditional process analysis: A regression-based approach, New York, NY: Guilford Press.

Kahneman, D. (1999). Objective happiness. In D. Kahneman, E. Diener, \& N. Schwarz (Eds.), Well-being: The foundations of hedonic psychology (pp. 3-25). New York, NY: Russell Sage Foundation.

Kopalle, P. K., \& Lehmann, D. R. (2001). Strategic management of expectations: The role of disconfirmation sensitivity and perfectionism. Journal of Marketing Research, 38, 386394. doi:10.1509/jmkr.38.3.386.18862 
Krueger, R. F., Hicks, B. M. \& McGue, M. (2001). Altruism and antisocial behavior: independent tendencies, unique personality correlates, distinct etiologies. Psychological Science, 12, 397-402. doi:10.1111/1467-9280.00373

Locke, E. A., \& Latham, G. P. (1990). A theory of goal setting and task performance. Englewood Cliffs, NJ: Prentice-Hall.

Luks, A. (1988, October). Helper's high. Psychology Today, 22, 39-42.

Lyubomirsky, S., Sheldon, K. M., \& Schkade, D. (2005). Pursuing happiness: The architecture of sustainable change. Review of General Psychology, 9, 111-131. doi:10.1037/10892680.9.2.111

Lyubomirsky, S., Tkach, C., \& Sheldon, K. M. (2004). [Pursuing sustained happiness through random acts of kindness and counting one's blessings: Tests of two six-week interventions]. Unpublished raw data.

Mastekaasa, A. (1994). Marital status, distress, and well-being: An international comparison. Journal of Comparative Family Studies, 25(2), 183-205. Retrieved from http://soci.ucalgary.ca/jcfs/

Michalos, A. C. (1980). Satisfaction and happiness. Social Indicators Research, 8, 385-422. doi:10.1007/BF00461152

Michalos, A. C. (1985). Multiple discrepancies theory (MDT). Social Indicators Research, 16, 347-413. doi:10.1007/BF00333288

Morrow-Howell, N., Hinterlong, J., Rozario, P. A. \& Tang, F. (2003). The effects of volunteering on the well-being of older adults. Journal of Gerontology: Social Sciences, 58B, S137-S145. doi:10.1093/geronb/58.3.S137 
Myers, D. G. (2000). The funds, friends, and faith of happy people. American Psychologist, 55, 56-67. doi:10.1037/0003-066X.55.1.56

Oettingen, G., \& Gollwitzer, P. M. (2001). Goal setting and goal striving. In A. Tesser \& N. Schwarz (Eds.), Blackwell handbook of social psychology: Intraindividual processes (pp. 329-347). Oxford, England: Blackwell.

Ojasalo, J. (2001). Managing customer expectations in professional services. Managing Service Quality, 11, 200-213. doi:10.1108/09604520110391379

Pham, L. B., \& Taylor, S. E. (1999). From thought to action: Effects of process-versus outcomebased mental simulations on performance. Personality and Social Psychology Bulletin, 25, 250-260. doi:10.1177/0146167299025002010

Post, S. G. (2005). Altruism, happiness, and health: It’s good to be good. International Journal of Behavioral Medicine, 12, 66-77. doi:10.1207/s15327558ijbm1202_4

Rucker, D. D, DuBois, D., \& Galinsky, A. D. (2011). Generous paupers and stingy princes: Power drives consumer spending on self and others. Journal of Consumer Research, 37, 1015-1029. doi:10.1086/657162

Schwartz, B. (2003). The paradox of choice: Why more is less. New York: Ecco.

Schwartz, C., Meisenhelder, J. B., Ma, Y., \& Reed, G. (2003). Altruistic social interest behaviors are associated with better mental health. Psychosomatic Medicine, 65, 778-785. doi:10.1097/01.PSY.0000079378.39062.D4

Sheldon, K. M., \& Lyubomirsky, S. (2006). Achieving sustainable gains in happiness: Change your actions, not your circumstances. Journal of Happiness Studies, 7, 55-86. doi:10.1007/s10902-005-0868-8 
Taylor, S. E., Pham, I., Rivkin, I., \& Armor, D. (1998). Harnessing the imagination: Mental simulation and self-regulation of behavior. American Psychologist, 53, 429-439. doi:10.1037/0003-066X.53.4.429

Thoits, P. A., \& Hewitt, L. N. (2001). Volunteer work and well-being. Journal of Health and Social Behavior, 42, 115-131. doi:10.2307/3090173

Thomas, W. C. (1981). The expectation gap and the stereotype of the stereotype: Images of old people. The Gerontologist, 21, 402-407. doi:10.1093/geront/21.4.402

Torelli, C. J., \& Kaikati, A. M. (2009). Values as predictors of judgments and behaviors: The role of abstract and concrete mindsets. Journal of Personality and Social Psychology, 96, 231-247. doi:10.1037/a0013836

Triandis, H. C., Bontempo, R., Leung, K., \& Hui, H. C. (1990). A method for determining cultural, demographic, and personal constructs, Journal of Cross-Cultural Psychology, 21, 302-318. doi:10.1177/0022022190213003

Tversky, A., \& Griffin, D. (1991). Endowment and contrast in judgments of well-being. In F. Strack, M. Argyle and N. Schwarz (Eds.), Subjective well-being: An interdisciplinary perspective (pp. 101-118). Oxford, England: Pergamon Press.

Vallacher, R. R., \& Wegner D. M. (1987). What do people think they’re doing? Action identification and human behavior. Psychological Review, 94, 3-15. doi:10.1037/0033295X.94.1.3

Vallacher, R. R., \& Wegner, D. M. (1989). Levels of personal agency: Individual variation in action identification. Journal of Personality \& Social Psychology, 57, 660-671. doi:10.1037/0022-3514.57.4.660 
Van Willigen, M. (1998, August). Doing good, feeling better: The effect of voluntary association membership on individual well-being. Paper presented at the meeting of the American Sociological Association, San Francisco, CA.

Vermunt, R., Spaans, E., \& Zorge, F. (1989). Satisfaction, happiness and well-being of Dutch students. Social Indicators Research, 21, 1-33. doi:10.1007/BF00302402

Vermunt, R., \& Steensma, H. (2001). Stress and justice in organizations: An exploration into justice processes with the aim to find mechanisms to reduce stress. In R. Cropanzano (Ed.), Justice in the workplace: From theory to practice (Vol. 2, pp. 27-48). Mahwah, NJ: Erlbaum.

Walker, J., \& Baker, J. (2000). An exploratory study of a multi-expectation framework for services, Journal of Services Marketing, 14, 411-431. doi:10.1108/08876040010340946

Weinstein, N. (1980). Unrealistic optimism about future life events. Journal of Personality and Social Psychology, 39, 806-820. doi:10.1037/0022-3514.39.5.806

Zauberman, G. \& Lynch, J. G., Jr. (2005). Resource slack and propensity to discount delayed investments of time versus money, Journal of Experimental Psychology: General, 134, 23-37. doi:10.1037/0096-3445.134.1.23

Zhang, Y., Fishbach, A., \& Dhar, R. (2007). When thinking beats doing: The role of optimistic expectations on goal-based choice. Journal of Consumer Research, 34, 567-578. doi:10.1086/520071 
Table 1

Experiment 1: Frequencies of Types of Acts Performed By Smile Goal vs. Happy Goal Condition Participants

\begin{tabular}{lcccc}
\hline & Happy & Smile & $\chi^{2}$ & $p$ \\
\hline$N$ for condition & 26 & 24 & & \\
Type of Act & & & & \\
$\quad$ Gave a gift or trinket & 4 & 3 & .09 & .77 \\
Told an amusing story or joke & 5 & 6 & .24 & .62 \\
Gave food or drink & 6 & 7 & .24 & .62 \\
Lent a helping hand & 4 & 3 & .09 & .77 \\
Unexpectedly contacted/reconnected with someone & 5 & 4 & .06 & .81 \\
Gave a card & 2 & 1 & .28 & .60 \\
Gave a compliment or said kind words & 3 & 3 & .01 & .92 \\
Shared an amusing video or picture & 2 & 3 & .32 & .57 \\
Lent an ear & 1 & 1 & $<.01$ & .95 \\
Engaged in physical contact & 1 & 1 & $<.01$ & .95 \\
\hline
\end{tabular}

Note: $\chi^{2}$ analyses compared the frequency with which each act type was mentioned in descriptions of acts performed by those in the abstract vs. concrete prosocial goal condition. 
Table 2

Experiment 2: Frequencies of Types of Acts Performed By Smile Goal vs. Happy Goal Condition Participants

\begin{tabular}{lcccc}
\hline & Happy & Smile & $\chi^{2}$ & $p$ \\
\hline$N$ for condition & 64 & 63 & & \\
Type of Act & & & & \\
$\quad$ Gave a gift or trinket & 12 & 9 & .46 & .50 \\
Told an amusing story or joke & 6 & 9 & .74 & .39 \\
Gave food or drink & 26 & 22 & .44 & .51 \\
Lent a helping hand & 16 & 14 & .14 & .71 \\
Unexpectedly contacted/reconnected with someone & 2 & 2 & $<.01$ & .99 \\
Gave a compliment or said kind words & 10 & 12 & .26 & .61 \\
Shared an amusing video or picture & 0 & 1 & 1.02 & .31 \\
Engaged in physical contact & 3 & 5 & .57 & .45 \\
Performed an amusing skill or talent & 1 & 2 & .36 & .55 \\
Took part in an activity or hobby with someone & 5 & 6 & .12 & .73 \\
\hline
\end{tabular}

Note: $\chi^{2}$ analyses compared the frequency with which each act type was mentioned in descriptions of acts performed by those in the abstract vs. concrete prosocial goal condition. 
Table 3

Experiment 3: Frequencies of Types of Acts Performed By Smile Goal vs. Happy Goal Condition Givers

\begin{tabular}{lcccc}
\hline & Happy & Smile & $\chi^{2}$ & $p$ \\
\hline$N$ for condition & 29 & 31 & & \\
Type of Act & & & & \\
Told an amusing story or joke & 14 & 18 & .58 & .45 \\
Discussed a future event & 12 & 9 & 1.00 & .32 \\
Gossiped about a mutual acquaintance & 4 & 3 & .25 & .62 \\
Playfully teased the receiver & 2 & 4 & .60 & .44 \\
Discussed a past event & 11 & 10 & .21 & .65 \\
Drew a picture & 1 & 2 & .29 & .59 \\
Engaged in physical contact & 4 & 2 & .90 & .34 \\
\hline
\end{tabular}

Note: $\chi^{2}$ analyses compared the frequency with which each act type was mentioned in descriptions of acts performed by those in the abstract vs. concrete prosocial goal condition. 
Table 4

Experiment 5: Frequencies of Types of Acts Performed By Abstract Goal vs. Concrete Goal Condition Participants

\begin{tabular}{lcccc}
\hline & Abstract & Concrete & $\chi^{2}$ & $p$ \\
\hline$N$ for condition & 35 & 35 & & \\
Type of Act & & & & \\
$\quad$ Recycled or reused something & 20 & 25 & 1.56 & .21 \\
Created or enhanced a recycling receptacle & 4 & 7 & .97 & .32 \\
Gardened or composted & 1 & 2 & .35 & .56 \\
Reduced emissions & 2 & 1 & .35 & .56 \\
Reduced energy consumption & 6 & 3 & 1.15 & .28 \\
Collected trash/non-recyclable waste & 3 & 1 & 1.06 & .30 \\
Educated someone about "green" behaviors & 4 & 2 & .73 & .39 \\
Reduced or prevented non-recyclable waste & 5 & 5 & $<.01$ & 1.00 \\
Other & 2 & 0 & 2.06 & .15 \\
\hline
\end{tabular}

Note: $\chi^{2}$ analyses compared the frequency with which each act type was mentioned in descriptions of acts performed by those in the abstract vs. concrete prosocial goal condition. 